\title{
A Tecelagem Manual em Minas Gerais: elementos para uma análise feminista da produção artesanal
}

\author{
Manual Weaving In Minas Gerais: Elements for a feminist analysis of threads \\ production
}

\author{
Amanda Motta Castro \\ Universidade do Vale do Rio dos Sinos - Brasil \\ motta.amanda@terra.com.br
}

\section{Edla Eggert}

Universidade do Vale do Rio dos Sinos - Brasil edla@unisinos.com.br

\section{Resumo}

Este texto articula e resgata saberes marginalizados, produzidos por mulheres que exercem a produção artesanal da tecelagem em Minas Gerais, estado do Sudeste brasileiro. O trabalho com os fios sai do espaço doméstico e privado para o público, pois nos dias atuais uma grande parte das artesãs ganha a vida tramando fios e produzindo artesanato. Este é desenvolvido pelas pessoas mais pobres do mundo e, dentre elas, por mulheres que buscam uma forma de sustento para si e suas famílias. O feminismo considera que as mulheres sempre trabalharam, entretanto suas produções ficaram esquecidas, sobretudo por terem sido realizadas no espaço privado. $\mathrm{O}$ trabalho artesanal é uma concretização entre o fazer e o pensar, que sinaliza a produção de conhecimento presente neste ofício. No caso estudado, trata-se de um conhecimento experienciado por mulheres devido à necessidade de trabalho $\mathrm{e}$ geração de renda, o que conduziu também os homens de Resende Costa a aprenderem a tecer. Com as mulheres, eles têm aprendido esta arte.

Palavras-Chave:Gênero; Artesanato; Tecelagem Manual; Minas Gerais.

\begin{abstract}
This text articulates and recovers marginalized knowledges, produced by women who work in the weaving handcraft production - in this specific case, in Minas Gerais, a state in Southeastern Brazil. The thread work leaves the domestic and private space towards the public one, since nowadays a great number of artisans earn their living weaving threads and producing handcraft. This is developed by the poorest people in the world, and, among them, women who seek a way to support themselves and their families. Feminism believes that women have always worked, nevertheless their production has been forgotten, especially for having been produced in the private space. Handcraft work is a realization between doing and thinking, that signalizes the production of knowledge present in this job. The case studied is about a knowledge experienced by women, given the need to work and make income, which also led the men in the city of Resende Costa to learn how to weave. With the women, they have learned this art.
\end{abstract}

Keywords: Gender; Handcraf; Manual Weaving; Minas Gerais. 


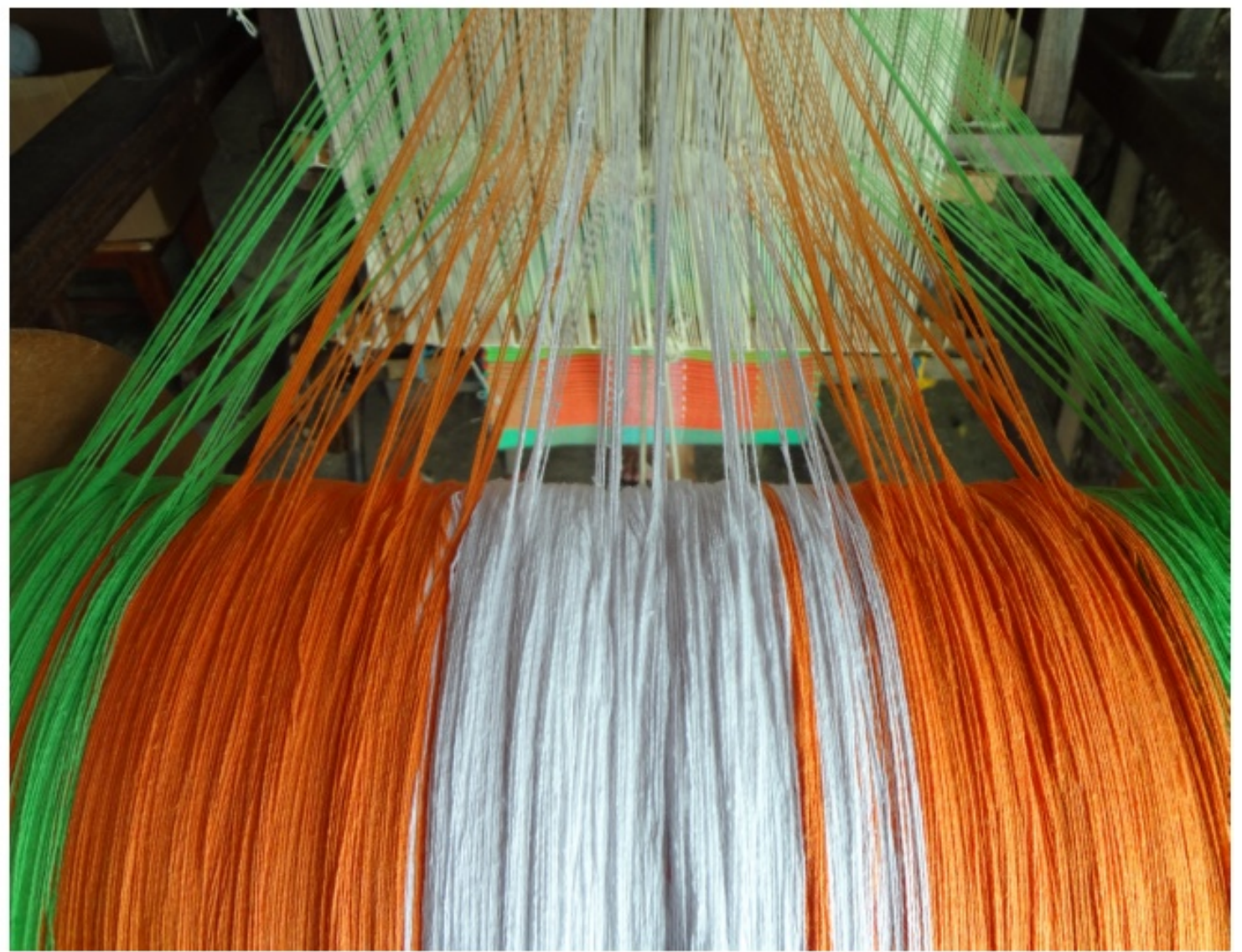

Fonte: acervo da pesquisadora (2012)

\section{Introdução}

$O$ artesanato corre junto com o tempo, e não quer vencê-lo.

$O$ artesanato não quer durar milênios nem está possuído pela pressa de morrer logo.

Transcorre com os dias, flui conosco desgasta-se pouco a pouco, não busca a morte nem a nega: aceita-

$a$.

$O$ artesanato nos ensina a morrer e, assim, nos ensina a viver. (OCTAVIO PAZ, apud LALADA DALGLIS, 2006, p.7)

Este artigo articula questões propostas, na pesquisa de doutorado que estamos desenvolvendo, sobre o trabalho da tecelagem, a partir da educação popular, do feminismo, sobretudo o que vem sendo produzido e problematizado a partir da América Latina. Nossa questão principal de pesquisa é: como ocorre o processo pedagógico de ensinar e aprender da tecelagem manual, em Resende Costa, no estado de Minas Gerais?

Deste modo, este artigo apresenta questões parciais já obtidas com a pesquisa em andamento.

De acordo com dados do Serviço Brasileiro de Apoio às Micro e Pequenas Empresas (SEBRAE, 2005), há no Brasil cerca de cinco milhões de pessoas trabalhando com o artesanato, $\mathrm{o}$ que representa $0,5 \%$ do PIB. O artesanato é definido como toda atividade produtiva de bens e artefatos realizada manualmente ou com a utilização de meios rudimentares com 
habilidade, destreza, qualidade e criatividade.

O Estado de Minas Gerais, localizado na Região Sudeste do Brasil, tem uma forte presença e tradição artesanal. Tal legado é conferido às indígenas, às escravas negras, trazidas da África, e às portuguesas. Dessa mistura, resulta a expressão artesanal mineira em diversas áreas: cerâmica, barro, pedra, madeira e fios.

Este artigo tem a intenção de abordar o artesanato dos fios, em especial a tecelagem manual, que, de acordo com Concessa Vaz de Macedo (2003; 2006), Kodaria Mitiko de Medeiros (2002) e Claudia Duarte (2002), foi exercida em Minas Gerais, sobretudo pelas mulheres. Atualmente, com base na pesquisa empírica, podemos verificar que este ofício ainda é desenvolvido e ensinado especialmente pelas mulheres.

Resende Costa localiza-se no interior de Minas Gerais, a $186 \mathrm{~km}$ da capital, Belo Horizonte, e faz parte da Região das Vertentes. A área total do município é de $631,561 \mathrm{~km}^{2}$. Sua criação ocorreu em $30 \mathrm{de}$ agosto de 1911. Sua história inicia, no entanto, na primeira metade do século XVIII, quando foi erguido um rancho para abrigar tropeiros e viajantes. A movimentação dos mesmos deu origem ao povoado de Lajes, hoje chamado de Resende Costa. Em 1749 foram construídas oito casas - entre elas a do Inconfidente José de Resende Costa - e a Capela Nossa Senhora da Penha de França.

No início, a pequena população dedicavase ao plantio de gêneros alimentícios e à criação de gado. Em 1912 o então povoado ganhou sua autonomia como município, recebendo o nome de Resende Costa, uma homenagem aos inconfidentes (pai e filho) que viveram ali nos primórdios da população.

Neste ano, Resende Costa está em festa, muitas comemorações para a cidade, que faz cem anos de emancipação política. Em 1912 a cidade passou a existir legalmente e tem sua autonomia no momento em que adquire liberação política (RESENDE, 2012). A cidade, segundo dados do IBGE de 2010, conta com 10.941 habitantes. Para atender esta pequena população, existe uma biblioteca municipal, que empresta livros para a comunidade, porém, não há cinema nem teatro. A cidade conta com um semáforo, dois postos de gasolina, três pousadas, uma praça, duas farmácias e noventa e oito lojas de artesanato.

Hoje, a principal atividade econômica do município é o artesanato têxtil, principalmente a confecção de peças para a casa. É a tecelagem manual que fornece trabalho para quem mora na cidade, tanto direto como indireto, haja vista que os pequenos restaurantes, postos de gasolina e bares de Resende Costa sobrevivem graças aos turistas que buscam a cidade para comprar peças de tecelagem nas lojas e nas casas.

$\mathrm{O}$ artesanato têxtil vem sendo desenvolvido na pequena cidade mineira, há muito tempo. Inicialmente, a atividade era feita para garantir o suprimento de utensílios para casa, segundo relato das tecelãs mais velhas da cidade. A tecelagem começou a ser feita para a venda por volta de 1950. Essa foi a forma que as mulheres da cidade encontraram para ter dinheiro e, ao mesmo tempo, ficar em casa para cuidar da família e dar conta do trabalho doméstico. A tecelã W, de 76 anos, conta:

Aconteceu foi isso: a gente tinha que ter dinheiro, e meu marido estava ganhando pouco e às vezes nem recebia, porque o serviço estava fraco. Então, comecei a fazer as mesmas colchas que fazia para a minha casa e também algumas iguais as que eu fiz para o meu enxoval. Comecei a vender aqui $e$ também em Belo Horizonte, em Tiradentes e São João Del Rei. Em 
pouco tempo, eu estava ganhando meu dinheirinho, pude criar meus filhos, nunca mais parei. Gosto de tecer, a gente ganha bem pouco, mas ganhamos. (TECELÃ W. Julho, 2012).

Assim como a tecelã W, muitas mulheres passaram a fazer o mesmo. E elas ensinaram suas filhas, netas e bisnetas. $\mathrm{Na}$ cidade onde acordamos com o barulho dos teares, o emprego para os homens estava cada vez mais difícil. Por conta disso, as mulheres resolveram ensinar a tecelagem para os homens. Hoje temos uma cidade onde a produção da tecelagem manual abarca homens e mulheres de todas as idades. Entretanto, as mulheres são as que mais tecem e em suas mãos encontra-se o processo de ensino e aprendizagem da tecelagem manual $^{1}$.

\section{Metodologia}

A metodologia utilizada na pesquisa que originou este artigo é qualitativa e assinala o compromisso com o feminismo. Levando em consideração as peculiaridades do lugar (trabalho e das pessoas), optamos em trabalhar com a observação participante e as entrevistas semiestruturadas e nos baseamos nos princípios da Pesquisa Participante. A pesquisa participante nasce nos anos 1960, em um contexto de lutas sociais, por iniciativa de pesquisadores e pesquisadoras, especialmente da América Latina, envolvidos com projetos de pesquisa social. Naquele contexto, ela visava à aproximação entre os pesquisadores e as pessoas inseridas na dura realidade que queriam transformar. Surgiu como contraponto e alternativa teóricometodológica aos modelos de ciências sociais de herança positivista e funcionalista, oriundos principalmente da América do Norte (BRANDÃO, 1986).
Participação é uma categoria muito discutida por Paulo Freire, sobretudo nas suas obras 'Política e Educação', 'A Educação nas cidades' e 'Educação e Mudança'. Para Freire, a participação pode ser entendida como exercício de voz, de ter voz, decidir, exercitar a cidadania e lutar por transformação social e emancipação (FREIRE, 2003). Dentro deste contexto de discussão e luta, surge a Pesquisa Participante: "A participação popular é a ferramenta capaz de romper com a tradição de sociedade elitista excludente". (FREIRE, 1991, p. 16).

A observação participante, muito desenvolvida pela Antropologia, foi retomada na Educação Popular e podemos citar os estudos realizados por Brandão (2003). Tal metodologia nos leva a partilhar o cotidiano, o que pensamos ser importante nesta pesquisa. A esse respeito, o autor menciona:

A observação participante, que obriga à partilha da vida do/com o outro [sic], e que nos envolve e faz se completarem estratégias (ou técnicas, se quiserem) de coleta de dados, como registro etnográfico em diários de campo, a entrevista, a história de vida, a exegese do visto e do ouvido (...). (FREIRE, 1991, p. 293).

O mesmo autor afirma que, a pesquisa requer partilha. Por esse motivo, em muitos momentos, vamos acompanhar o cotidiano, através desta metodologia. Temos material coletado durante as observações participantes realizadas em Resende Costa em 2011 e 2012.

Optamos pela entrevista individual que, assim como a observação participante, também é bastante utilizada em pesquisas qualitativas. Realizamos entrevistas semiestruturadas que possibilitam fazer:

(...) certos questionamentos básicos 
apoiados em teorias e hipóteses, que interessam à pesquisa, e que, em seguida, oferece amplo campo de interrogativas, fruto de novas hipóteses que vão surgindo à medida que se percebem as respostas do informante. (TRIVIÑOS, 1987, p.146).

Segundo Rosalia Duarte (2004), entrevistas são fundamentais, quando há necessidade e/ou desejo de mapear práticas, crenças e valores. Para isso, sabemos que a entrevista requer que sejamos boas entrevistadoras para, de fato, termos possibilidade não apenas de ouvir, mas fazêlo de forma ativa, isto é, ouvir atentamente. Desse modo, demonstramos interesse na fala da entrevistada e participamos da entrevista com gestos que evidenciem a entrevistada que ela ouvida. Sobre isso, José Magnani (1986) destaca:

Além de ouvir, o pesquisador [sic] precisa ficar atento às expressões utilizadas pelo entrevistado [sic], pois ele pode simular palavras e conceitos que não são utilizados no seu dia a dia, tentando mostrar aquilo que ele acha que o entrevistador [sic] quer ouvir. (p. 97).

Portanto, nossa proposta metodológica integra a observação participante e as entrevistas individuais, buscando a escuta sensível e a observação atenta para os movimentos da empiria que vão para além da palavra. Sabemos que não apenas o dito constitui uma pesquisa, mas também o não dito, como nos ensina Elaine Neuenfeldt (2005; 2008).

\section{Artesanato: uma Produção à Margem}

No artigo 'Instituições do Estado e a produção e reprodução da desigualdade na América Latina', Laura Mota Días (2007) faz um mapa da questão da desigualdade na América Latina e Caribe. Esta, conforme a autora é atualmente o lugar mais desigual do planeta. Neste estudo, temos facetas distintas da desigualdade: econômicas, políticas e socioculturais. A autora aponta que a desigualdade acompanha a história da América Latina. Além do fato da concentração de renda, as questões que estruturaram esta desigualdade vão, além disso: "a desigualdade não só foi produto da concentração da renda, como também das interações sociais, marcadas pela existência de relações assimétricas que se estabeleceram entre os colonizadores europeus e a população originária da América Latina" (DÍAS, 2007, p. 130).

Sabemos que essa desigualdade ocorre marcando distintos lugares, mais importantes ou menos. As mulheres foram destinadas aos trabalhos domésticos, de cuidado e que contemplassem as qualidades ditas femininas, marcando assim o lugar das mulheres na sociedade. Para a autora, a questão de gênero é fundamental para compreendermos a desigualdade:

O gênero é um dos fatores medulares na construção de desigualdades. Para além das diferenças biológicas, foram estruturadas distinções sociais e culturais entre homens e mulheres, dentro das quais se estabelecem hierarquias de poder, de status e de renda. Finalmente, os atributos individuais constroem-se socialmente como resultado de processos históricos. (DÍAS, 2007, p.128). 
Com a problematização do artesanato, abordamos questões fundamentais para a compreensão deste trabalho: o primeiro deles é destacado por Eli Bartra (2004), quando afirma que o artesanato é desenvolvido pelas pessoas mais pobres do mundo. O segundo é destacado por Eggert (2006; 2010; 2011), Macedo (2003; 2006), Mitiko, (2002) e Duarte (2002), que afirmam que o artesanato ligado ao fio - principalmente a tecelagem é produzido principalmente por mulheres.

Sendo assim, o artesanato que pesquisamos é produzido na América Latina por mulheres, sobretudo de classes populares. Portanto, estudamos uma produção que fica à margem, por ser oriunda de um lugar desigual. Além disso, este trabalho é produzido por pessoas de um gênero considerado, na hierarquia social vigente, de menor valor, menor poder, menor renda e mais pobre. Podemos agregar aqui mais uma questão essencial: no artesanato, não temos no Brasil uma educação formal que dê às mulheres que trabalham na área uma certificação. Entretanto, sabemos que o trabalho artesanal exige um processo de ensino e aprendizagem, de qualificação e aperfeiçoamento, mesmo que não exista uma certificação formal deste processo.

Em seu livro $O$ Artífice, Richard Sennett (2009) indica que são necessárias dez mil horas de experiência para termos uma artesã qualificada. Em vista disso, quando discutimos o artesanato, trata-se de horas de estudo, mesmo que esse processo não seja formalmente reconhecido. $\mathrm{O}$ autor afirma que a habilidade artesanal requer um alto grau de aprendizagem, logo, podemos afirmar que, ao olharmos um trabalho de tecelagem, como uma colcha bem tramada, com suas diversas cores e formatos, é fato que a artesã que a fez aprendeu a técnica, a arte e o conhecimento dos teares.

Durante a empiria, tecelãs apontam as principais 'qualidades' de uma boa trabalhadora desta área. São elas: paciência; criatividade; rapidez; capacidade de lidar com a dor e capacidade de fazer muitas tarefas ao mesmo tempo.

- Paciência: horas em um tear de pedal trabalhando com as mãos e os pés, combinação de cores, criando peças e fazendo arte.

- Criatividade: para criar na tecelagem manual é necessária criatividade para jogar com as cores e assim ter peças harmoniosas. A tecelagem é tão complexa e criativa que as mulheres desenvolveram ao longo dos anos uma linguagem própria da tecelagem como uma partitura musical. As mulheres dedicam horas à criação de repassos, isto é, os desenhos que serão tecidos em colchas, mantas, tapetes, toalhas e outros.

- Rapidez: os teares em Resende Costa começam cedo, por volta das $5 \mathrm{~h} 30$ e terminam tarde. Em algumas casas, as mulheres relatam que terminam o acabamento dos tapetes que envolvem o cortar e o amarrar as pontas para não se soltarem apenas depois da novela, que termina por volta das $22 \mathrm{~h}$. A rapidez do trabalho da tecelagem acontece devido à necessidade de dinheiro. Nesta atividade, o pagamento é por peça produzida. Portanto, quanto mais se tece mais se ganha.

- Dor: segundo vários relatos obtidos durante a empiria, são constantes as dores nas costas, pernas e nos braços pelo trabalho repetitivo. Tendinite, varizes e hérnia são os desdobramentos de várias horas ao tear.

- Todo conhecimento da tecelagem, a capacidade de simultaneidade e criação são perdidos em um processo invisível e que está à margem porque é um conhecimento feminino, tramado no cotidiano privado, o lugar onde as mulheres desenvolveram seus conhecimentos. Sendo assim, temos um trabalho extremamente desvalorizado 
financeiramente, e esse conjunto de fatores acarreta a consideração da tecelagem como um trabalho 'menor'.

\section{Contribuições do Feminismo para (re)pensar o Artesanato}

A renda, o bordado, o crochê, a costura e a tecelagem fazem parte do artesanato ligado aos fios, o qual é considerado como uma produção tipicamente feminina. Os livros de histórias apresentam imagens de mulheres no mundo privado, realizando trabalhos manuais.

O trabalho dos fios como um 'atributo feminino' vem de longa data. Em suas origens, a doutrina da Igreja geralmente considerava o tempo livre como uma tentação, e o lazer como um convite para indolência. Esse temor se aplicava principalmente às mulheres. Eva encarnava a tentação, distraindo o homem do seu trabalho. Os patriarcas da Igreja consideravam as mulheres especialmente tendentes à licenciosidade sexual se nada tivesse para ocupar as suas mãos. Tal preconceito deu origem a uma prática: a tentação feminina podia ser combatida por meio de um artesanato específico, o da agulha, mantendo permanentemente ocupadas as mãos das mulheres (SENNETT, 2009).

A agulha como remédio para a ociosidade feminina remonta um dos primeiros patriarcas, Jerônimo. Como costuma acontecer com os preconceitos que amadurecem com o tempo, essa denegação sexual também se tornou, no início da Idade Média, um motivo de honra (SENNETT, 2009).

O tempo passou e, nos dias atuais, também são as mulheres as que mais tecem; hoje os fios saem do privado para o público. Hoje, mulheres 'ganham' a vida entre os fios, trabalhando no artesanato como uma forma de atender a demanda doméstica de cuidado da casa e das crianças, bem como das atividades profissionais, realizadas, muitas vezes, em casa. As mulheres realizam ambas as atividades num processo de simultaneidade presente no cotidiano das mulheres pela necessidade. Sobre esse processo, a tecelã $\mathrm{V}$, de 34 anos de idade, e que há 24 anos ganha seu sustento no tear em Resende Costa afirma: "O bom desse trabalho é que eu trabalho em casa né, assim eu cuido da casa, cuido dos filhos e ainda ganho um ganhozinho. Eu não tenho hora certa pra tecer, teço fazendo todas essas coisas juntas" (tecelã V, Julho, 2012).

Entendemos que entre os fios existe processo, conhecimento, técnica, arte e complexidade. Entretanto, por ser uma produção feminina, sua complexidade dá lugar ao invisível. Sobre ser essa uma atividade tipicamente feminina, a tecelã $\mathrm{D}$ comenta:

Quem manda nos teares são as mulheres, uai. Foram nós que começamos a tecer. Eu teço há 60 anos, estou com 75. Ensinei todas as minhas filhas a tecerem. Eu aprendi com a minha mãe, isso porque minha bisavó tecia, minha avó tecia, minha mãe tecia. Eu teci muitos anos, mas agora não tenho mais força nas pernas. Mas minhas filhas tecem e agora elas tem lojas lá no asfalto. Todas as mulheres da família teceram, os homens, não. Até hoje aqui, em Resende Costa, as mulheres tecem, mas eu não sei por quê. Mas as mulheres tecem mais. (Julho de 2011).

Sendo a tecelagem predominantemente feminina, o artesanato dos fios passa a ser um processo invisível, pouco reconhecido e financeiramente desvalorizado. Tais aspectos, 
segundo Eggert (2004), tornam precário o trabalho do artesanato dos fios, que, enquanto produção das mulheres, fica à margem. Sobre o processo de desvalorização e precariedade, a tecelã V diz:

Acho que meus filhos vão ter outros caminhos, eles vão estudar - a gente não estudou quase. Eu quero que eles estudem, que formem, que arrumem qualquer coisa na vida e não fiquem igual nós, batendo tear o dia inteiro quando dá (...) É um trabalho bonito sabe, eu gosto, mas é um trabalho dolorido. (Julho, 2012).

O feminismo historiciza que as mulheres, ao longo da trajetória da humanidade, sempre trabalharam. Michelle Perrot (2007) é uma das pesquisadoras que faz tal afirmação e acrescenta que o trabalho feminino foi silenciado, sobretudo por ser um trabalho da "ordem" do cotidiano na vida das mulheres. Ora um trabalho doméstico, ora um trabalho artesanal, ou como ajudante do marido no trabalho informal no comércio e artesanato. Empiria e teoria indicam a mesma direção: invisibilidade do trabalho das mulheres. A tecelã $\mathrm{F}$, de 75 anos, começou a tecer com 13 anos, parou de tecer há 2 anos por dificuldades físicas. Ela aprendeu a arte com as suas tias:

Tinha uma época que meu marido era empregado, e o patrão não pagou ele. Então, eu tecia, e vinham uns rapazes de Belo Horizonte que compravam as minhas colchas para vender de novo em Belo Horizonte. Então, eu ajudava ele [o marido] nas despesas da casa. Eu também ajudava na casa da minha mãe com as despesas da casa. (Julho, 2012).
Com base na afirmação de Perrot (2007) de que as mulheres sempre trabalharam, podemos acrescentar que as mulheres tiveram um processo de ensino e aprendizagem desenvolvido no cotidiano do dia a dia. Muitos conhecimentos ligados ao mundo do privado estão nas mãos das mulheres e vem sendo passados de geração em geração. Sobre esse conhecimento, Eggert (2006) faz a seguinte indagação:

Fazer o pão e conversar - aprender de outras formas; fazer o cabelo e conviver - perceber o que é o belo num salão de beleza; cozinhar e duvidar dos modos de fazer - ousar sistematizar o cotidiano da química da cozinha; partejar e pensar o que faz nascer; tricotar, tecer, bordar e analisar o que tramam as mulheres... Seriam objetos de produção de conhecimento? Aquilo que por séculos nos limitou em espaços esquadrinhados pelo poder patriarcal poderia ser o próprio lugar para um salto de qualidade na nossa reflexão? (p.101).

Podemos citar muito sobre o conhecimento das mulheres: manipulação de ervas, receitas de cozinha, economia, saber da ginecologia e obstetrícia - haja vista, as parteiras, que, durante séculos, foram responsáveis pelo nascimento -, ensinamentos relacionados à criação de crianças, artesanato, entre outros. Levando em consideração o pensamento de Eggert, podemos afirmar que onde a sociedade patriarcal nos "colocou", nós, mulheres, desenvolvemos uma produção de alta qualidade.

Observamos que muitos saberes ditos 'femininos', ao serem transferidos e capturados pelas mãos dos homens, tornaram-se saberes altamente qualificados, 
sistematizados e formais. Um exemplo disso é a cozinha: como circula em diversos espaços, durante séculos, o conhecimento da alimentação esteve nas mãos das mulheres, mas hoje a cozinha passa a ser um saber extremamente complexo, com formação em nível de graduação, e os melhores chefes de cozinha são homens.

Assim, a masculinização de um trabalho feminino, tema amplamente discutido na tese de doutorado de Aline Lemos da Cunha (2010), conferiu status e qualificação a um trabalho anteriormente menor, posto que "quando falamos relações de gênero, estamos falando de poder. $\mathrm{Na}$ medida em que as relações existentes entre masculino e feminino são relações desiguais, assimétricas, mantém a mulher subjugada ao homem e ao domínio patriarcal" (COSTA, 2010, p. 5). Essa desigualdade também ocorre nas relações de trabalho e nos processos de ensinar e aprender.

Todo esse conhecimento vem sendo passado através dos tempos pelas mãos das mulheres. Entretanto, mesmo sendo fundamental para nossa sobrevivência, fica à margem e socialmente invisibilizado, pois é um conhecimento não-formal, vindo do cotidiano e está estreitamente ligado ao mundo do privado. Desse modo, tais conhecimentos são reconhecidos muitas vezes de forma pejorativa como 'coisinha de mulher'. Temos, nesse contexto, uma Pedagogia tão invisível que, muitas vezes, em entrevistas, tecelãs e tecelões afirmam não saber exatamente como aprenderam a tecer: "pois eu não lembro como foi que eu aprendi a tecer, eu acho que aprendi olhando, acho que foi assim, acho que ninguém me ensinou" (Tecelão P, 2012). Após essa afirmação, pergunto se ele aprendeu olhando. Depois de alguns segundos em silêncio, $\mathrm{P}$ responde: "Minha mãe. Vi a minha mãe tecer e por vezes brincava no tear com ela" (2012, s.p.).

Deste modo, temos o conhecimento das mulheres inferiorizado porque o seu trabalho e seus processos de ensinar e aprender estão historicamente ligados ao mundo privado, ao qual elas estiveram vinculadas por um longo período. Segundo Prisca Kergoat (2011), no fim do século XIX, surgiu a noção de 'ofício de mulher', ligada às, então chamadas, qualidades 'naturais e inatas' femininas: o cuidado com o outro, o amor e a maternidade.

A desvalorização do trabalho feminino estaria relacionada à falta de necessidade de aprendizagem e de qualificação (KERGOAT, 2011). Marcela Lagarde (2005) também aponta nesta direção ao afirmar que tal desvalorização acontece devido à ideia muito comum na sociedade - de que as mulheres têm como última e principal missão a maternidade, ou seja, o cuidado para com o outro é a sua tarefa básica e principal.

Segundo Eggert (2004), um dos motivos da desvalorização do trabalho das mulheres acontece devido à sociedade reafirmar a mulher como a responsável pela esfera privada, devendo-se envolver com o trabalho doméstico, o amor materno e o cuidado com o outro. Amiée Montiel (2007) argumenta que o trabalho feminino deve socialmente ser realizado 'por amor'.

De acordo com Sennet (2009), “a cabeça e a mão não são separadas apenas intelectualmente, mas também socialmente" (p. 57). Essa separação histórica levou os homens a ficarem com o trabalho 'da cabeça', e as mulheres com o trabalho 'das mãos', pois, no imaginário popular, o trabalho com as mãos é menos complexo e exige menos qualificação (KERGOAT, 2011).

$\mathrm{O}$ artesanato realizado com as mãos, muitas vezes, é aprendido no trabalho simultâneo de mulheres entre o tear, o doméstico e a criação dos filhos. Logo, esse processo exige menos qualificação. Sobre seu processo de aprendizagem nos teares mineiros, a tecelã $\mathrm{T}$ afirmou que aprendeu a 
tecer sozinha, ou seja, ninguém a ensinou. Quando perguntei "Como assim, sozinha?", ela respondeu:

\section{(...) é, aprendi sozinha, minha vó e} minha mãe ficavam ali no tear tecendo, e eu ia vendo, até o dia que minha mãe disse: " $T$, entra no tear". Então, eu teci o primeiro tapetinho e nunca mais saí do tear. Hoje, sustento meus filhos do tear. (tecelã T, Julho, 2012).

O trabalho manual dos fios, em especial o da tecelagem, foi historicamente invisibilizado, pois está na ordem do privado e, por isso, é compreendido como um conhecimento inato e natural das mulheres, não um ofício complexo.

\section{Conclusões Parciais}

Tendo como base nossa pesquisa empírica e o campo teórico, podemos afirmar que a tecelagem manual é hoje um processo invisível, pouco reconhecido e financeiramente desvalorizado. Este processo, segundo Eggert (2004), torna precário o trabalho do artesanato dos fios, além de deixar à margem a produção das mulheres. O feminismo vai mostrar que, embora as mulheres sempre tenham trabalhado (PERROT, 2007), a sua produção ficou esquecida porque, ao longo dos tempos, foi realizada no privado. A afirmação é constatada através da empiria: as mulheres que compõem este trabalho são mulheres de classe popular, com pouco grau de estudo formal, que quase sempre trabalharam com a tecelagem manual; e o trabalho ainda é realizado principalmente em suas casas pelas mulheres.

Para Eli Barta (2008), é preciso reverter a dupla marginalização intelectual da arte popular: "El arte popular es considerada de segunda, elaborada por gente también de segunda" (p. 12). A autora argumenta ainda que a atividade criativa desenvolvida pelas mulheres na arte popular é apenas mais umas das muitas produções das mulheres que ficam invisíveis. Afirma que a arte desenvolvida pelas mulheres é tão invisível quanto o trabalho doméstico realizado diariamente por elas no cotidiano ordinário (GEBARA, 2008). Para o feminismo, o privado é político, e o trabalho diário de fazer esse movimento - politizar o privado - é uma das formas de reverter a marginalização do trabalho desenvolvido pelas mulheres. Sobre isso, Sennet (2009) analisa:

Em sua maioria os ofícios e artífices domésticos têm um caráter diferente dos trabalhos que hoje se executam fora de casa. Por exemplo, não consideramos os cuidados paternos como uma atividade no mesmo sentido que atribuímos ao ofício de bombeiro ou à programação de computadores, muito embora o alto grau de capacitação especializada seja necessário para ser um bom pai ou uma boa mãe. (p.33-34).

Nancy Cardoso Pereira (2009) mostra que "A contribuição ética do feminismo se dá na insistência de que o pessoal é político, o cotidiano é histórico, a reprodução é produtiva, a produção é distributiva, o consumo criativo" (p. 232). Em vista disso, o feminismo vem contribuindo para visibilizar o invisível, destacando que o que é tecido no cotidiano da casa, na vida privada das mulheres também é político, histórico e produtivo. Além disso, a denúncia de que a sociedade patriarcal inferioriza o conhecimento das mulheres afirma que entre os fios existe conhecimento. 
1 Afirmação feita com base na pesquisa empírica realizada em julho de 2011 e julho de 2012.

\section{Referências}

BARTRA, Eli. Rumiando en torno a lo escrito sobre mujeres y arte popular. La ventana, n. 28 , p. 7 - 23, 2008.

BARTRA, Eli. (org). Criatividad invisible. Mujeres e arte popular en América Latina e Caribe. Xochimilco: Universidade Autônoma Metropolitana, 2004.

BRANDÃO, Carlos Rodrigues. A pergunta a várias mãos - a experiência da pesquisa no trabalho do educador. São Paulo: Cortez, 2003.

COSTA, Ana Alice. Gênero, poder e empoderamento das mulheres. Disponível em:

$<$ http://www.agende.org.br/docs/File/dados_ pesquisas/feminismo/Empoderamento \%20\%20Ana\%20Alice.pdf $>$. Acesso em 29 de Julho de 2014.

CUNHA, Aline Lemos. Histórias em múltiplos fios: o ensino de manualidades entre mulheres negras em Rio Grande (RS - Brasil) e Capitán Bermúdez (Sta. Fe Argentina) (re)inventando pedagogias da não-formalidade ou das tramas complexas. 2010. Tese (Doutorado em Educação). Universidade do Vale do Rio dos Sinos, São Leopoldo.

DÍAS, Laura Mota. Instituições do Estado e a produção e reprodução da desigualdade na América Latina. Porto Alegre: Editorial CLACSO, 2007.

DUARTE, Claudia Renata. A tecelagem manual no Triângulo Mineiro - história e cultura material. Uberlândia: EDUFU, 2009.

DUARTE, Rosália. Entrevistas em pesquisas qualitativas. Revista Educar, v. 24, n. 24, p. 213 - 225, 2004.

EGGERT, Edla. Doméstico - espaços e tempos para as mulheres reconhecerem seus corpos e textos. In: STRÖHER, Marga; DEIFELT, Wanda; MUSSKOPF, André (Orgs). À flor da pele: ensaios sobre gênero e corporeidade. São Leopoldo: Sinodal; CEBI, 2004. p. 225-241.

EGGERT, Edla. A graça do mundo do lado de baixo do Equador. In: PEREIRA, Nancy; EGGERT, Edla; MUSSKOPF, André S. A graça do mundo transforma Deus. Porto Alegre: Ed. Metodista, 2006.

EGGERT, Edla. Tramando outros conhecimentos: artesanato e debate temático. VII Seminário Internacional Fazendo Gênero: Gênero e Preconceitos, 7, Universidade Federal de Santa Catarina, Florianópolis. Anais do VII Seminário Internacional Fazendo Gênero. Disponível em: <http://www.fazendogenero.ufsc.br/7/>. Acesso em 23 de Janeiro de 2013.

EGGERT, Edla. Trabalho precário $\mathrm{x}$ profissionalização de tecelãs: um desafio para a formação educacional no campo do artesanato gaúcho. VIII Congresso Iberoamericano de Ciência, Tecnologia e Gênero, 8, Universidade Tecnológica Federal do Paraná, Curitiba. Anais do VIII Congresso Iberoamericano de Ciência, Tecnologia e Gênero. Disponível em: $<$ http://arcaz.ppgte.ct.utfpr.edu.br/eventos/cic $\mathrm{tg} />$. Acesso em 23 de Janeiro de 2013.

EGGERT, Edla. (Org.). Processos educativos no fazer artesanal de mulheres 
do Rio Grande do Sul. Santa Cruz do Sul: EDUNISC, 2011.

FREIRE, Paulo. Pedagogia da Esperança. Um reencontro com a pedagogia do oprimido. São Paulo: Paz e Terra, 2003.

FREIRE, Paulo. Pedagogia da autonomia: saberes necessários à prática educativa. $25^{\mathrm{a}}$ ed. São Paulo: Paz e Terra, 1991.

GEBARA, Ivone. As epistemologias teológicas e suas consequências. In: NEUENFELDT, Eliane; BERGSCH, Karen; PARLOW, Mara (Org.). Epistemologia, violência, sexualidade: olhares do II Congresso Latino-Americano de Gênero e Religião. São Leopoldo: Sinodal, 2008.

KERGOAT, Prisca. Oficio. In: HIRATA, Helena; LABORIE, Franloise (org). Dicionário Crítico do Feminismo. São Paulo: Unesp, 2011, p. 159 - 166.

LAGARDE, Marcela. Cautiverios de las mujeres: madresposas, monjas, putas, presas y locas. $4^{\mathrm{a}} \mathrm{ed}$. Ciudad del México: UNAM, 2005.

MACEDO, Concessa Vaz de. A indústria têxtil, suas trabalhadoras e os censos da população de Minas Gerais do século XIX: uma reavaliação. Varia História, v. 22, n. 35, p. $207-232,2006$.

MACEDO, Concessa Vaz de. A produção têxtil de fios e tecidos em Minas Gerais. 2003 disponível em: $<$ http://www.mao.org.br/fotos/pdf/biblioteca/ macedo_01.pdf $>$. Acesso em 20 de janeiro de 2012.

MAGNANI, José Guilherme C. Discurso e representação, ou de como os Baloma de Kiriwina podem reencarnar-se nas atuais pesquisas. In: CARDOSO, Ruth. A aventura antropológica: teoria e pesquisa. Rio de Janeiro: Paz e Terra, 1986. p. p 127 - 140.

MEDEIROS, Mitiko Kodaira de. O segredo da trama: desvendando a comunicação na tecelagem popular brasileira. 2002. Dissertação (Mestrado em Comunicação). Universidade Paulista, São Paulo.

MONTIEL, Amiée. Por la visibilidad de las amas de casa: rompiendo la invisibilidad del trabajo doméstico. Política y cultura, n.28, p. $181-200,2007$.

NEUENFELDT, Eliane; BERGSCH, Karen; PARLOW, Mara (Org.). Epistemologia, violência, sexualidade: olhares do II Congresso Latino-Americano de Gênero e Religião. São Leopoldo: Sinodal, 2008.

NEUENFELDT, Eliane. Diálogo entre a leitura popular e a leitura feminista da Bíblia. disponível em: $<$ http://www3.est.edu.br/publicacoes/estudos teologicos/vol4502_2005/et2005-

2 i_eneuenfeldt.pdf $>$. Acesso em outubro de 2012 .

PERROT, Michelle. Minha história das mulheres. São Paulo: Contexto, 2007.

PEREIRA, Nancy Cardoso. O papel é paciente, a história não é: cotidiano sagrado, educação e diversidade religiosa no Brasil. In: OLIVEIRA, Lilian; CECCHETTI, Elcio; CESARO, Rosa Assunta de (Org.). Cultura e Diversidade Religiosa na América Latina Pesquisas e Perspectivas Pedagógicas. Blunemau: Edifurb, 2009.

SANTOS, Boaventura de Souza; MENESES, Maria Paula. Epistemologias do Sul. Coimbra: CES, 2009. 
SENNETT, Richard. O Artífice. Rio de Janeiro: Record, 2009.

STRECK, Danilo. Entre emancipação e regulação: (des)encontros entre educação popular e movimentos sociais. Revista Brasileira de Educação, v.15, n. 44, p. 300 310, 2010 .

TRIVIÑOS, Augusto N. S. Introdução à pesquisa em ciências sociais: a pesquisa qualitativa em educação. São Paulo: Atlas, 1987. 